DOI: $10.17805 /$ zpu.2018.3.18

\title{
Позиции взаимодействия студентов в контексте проблем обеспечения психологической безопасности личности *
}

\author{
В. Г. МАРАЛОВ \\ ЧЕРЕПОВЕЦКИЙ ГОСУДАРСТВЕННЫЙ УНИВЕРСИТЕТ, \\ А. А. ФОРТУНАТОВ, М. Ю. ШОНИН \\ МОСКОВСКИЙ ГУМАНИТАРНЫЙ УНИВЕРСИТЕТ
}

Актуальность проблемы обусловлена значимостью выявления факторов, обусловливающих принятие людьми позиций взаимодействия: принуждения, манипулирования, ненасилия и невмешательства, которые могут быть оценены с точки зрения безопасности. Цель исследования состояла в выявлении взаимосвязи позиций взаимодействия с потребностями в опасности и безопасности, мотивацией достижения успеха и избегания неудач, склонностью к риску, сензитивностью (чувствительностью) к угрозам и выбором адекватных или неадекватных способов реагирования в ситуациях опасности. Использовались авторские опросники на выявление позиций взаимодействия у студентов, потребностей в опасности и в безопасности, сензитивности к угрозам, выборов адекватных или неадекватных способов реагирования в ситуациях опасности, а также тесты Т. Элерса на выявление мотивации достижения успеха и избегания неудач, тест Г. Шуберта, диагностирующий готовность личности к риску. Всего в исследовании приняли участие 122 студента Московского гуманитарного университета и Череповецкого государственного университета в возрасте от 18 до 22 лет. Исследование проводилось в 2018 г.

В результате была выявлена положительная связь позиции принуждения с потребностью в переживании чувства опасности, стремлением к игнорированию угроз, мотивацией достижения. Позиция манипулирования обнаружила такие же связи, кроме того, выявлена связь с сензитивностью к угрозам. Позиция ненасилия положительно коррелирует с потребностью в обеспечении безопасности, стремлением к избеганию неудач, сензитивностью к угрозам и выбором адекватных способов реагирования. Позиция невмешательства положительно связана в первую очередь с потребностью в переживании чувства безопасности, а также с потребностью в обеспечении безопасности, выраженным стремлением к избеганию неудач, стремлением к преувеличению значения опасностей. Проведенное исследование со всей очевидностью показало, что в процессе формирования у студентов способности к ненасильственному взаимодействию необходимо обращать внимание не только на ценностную сторону ненасилия как оптимального способа взаимодействия людей друг с другом, но и на мотивационные факторы, в частности на формирование потребности в обеспечении безопасности. Полученные результаты могут быть использованы при разработке специальных программ и технологий формирования у студентов - будущих педагогов, психологов, социальных работников, дефектологов, врачей и т. п. способности к ненасильственному взаимодействию.

Ключевые слова: взаимодействие; позиции взаимодействия; педагогика ненасилия; мотивация; потребность в опасности; потребность в безопасности; мотивация достижения успеха; склонность к риску, сензитивность к угрозам; психология безопасности личности

\section{ВВЕАЕНИЕ}

$\mathrm{B}$ ся жизнь и деятельность человека проходят в процессе взаимодействия с другими людьми. Какую бы сферу мы ни взяли, везде мы сталкиваемся с необходимостью согласовывать свои действия, свое поведение с действиями, поведением и поступками других. Такое взаимодействие может носить раздичный характер. Оно может быть

* Исследование выполнено при финансовой поддержке РФФИ в рамках научного проекта № 18-013-00151.

The research was financially supported by RFBR within the scientific project No. 18-013-00151. 
деловым, дружеским, напряженным, конфликтным, нейтральным и др. Иными словами, любое взаимодействие может быть проанализировано с точки зрения психологической безопасности.

В зависимости от ориентации индивида на ценности принуждения или ненасилия мы выделяем четыре позиции взаимодействия: принуждения, манипулирования, ненасилия и невмешательства (Маралов, Ситаров, 2017). Принуждение проявляется в таких действиях одного человека по отношению к другому (другим людям) человеку, как приказ, требование, давление, понуждение, унижение, подчинение, вплоть до проявлений агрессии. Манипулирование - это более мягкая форма принуждения, в основе которой лежат лесть, обман, психологические игры и т. п. Ненасилие всегда ориентировано на сотрудничество, взаимопонимание, учет интересов каждой стороны взаимодействия и проявляется в помощи, способности идти на компромисс, в ряде случаев - в терпении, умении прощать и т. А. Позиция невмешательства характеризуется пассивностью человека, отказом от каких-либо действий, обусловлена нередко стремлением избегать трудностей и неприятностей.

Если проанализировать эти позиции взаимодействия с точки зрения безопасности, то позиции принуждения и манипулирования могут быть признаны в ряде случаев как опасные, особенно тогда, когда человек, принимающий данные позиции, своими действиями наносит ощутимый ущерб противоположной стороне, а позиции ненасилия и невмешательства - как безопасные. Невмешательство безопасно, так как личность не производит никаких действий, ненасилие же безопасно по определению, поскольку оно ориентировано изначально на непричинение вреда противоположной стороне.

В соответствии с этим возникает вопрос: какие факторы обусловливают принятие индивидом той или иной позиции?

На наш взгляд, можно выделить по крайней мере две группы факторов. Первая группа связана с сознательным усвоением и принятием ценностей принуждения или ненасилия. Вторую группу составляют многообразные потребности и мотивы человека. Важнейшими из них мы считаем уровень выраженности потребностей в опасности и безопасности, мотивы достижения успеха и избегания неудачи, склонность к риску, а также специфическое отношение человека к опасностям.

В настоящей статье мы будем вести речь о второй группе факторов. Цель исследования состояла в выявлении взаимосвязи позиций взаимодействия с потребностями в опасности и безопасности, мотивацией достижения успеха и избегания неудач, склонностью к риску, сензитивностью (чувствительностью) к угрозам и выбором способов реагирования в ситуациях опасности. В качестве гипотез исследования выступили следующие предположения:

- принятие индивидом той или иной позиции в процессе взаимодействия будет обусловлено уровнем выраженности потребности в переживании чувства опасности, в переживании чувства безопасности, в обеспечении безопасности, доминированием мотивации достижения успеха или избегания неудач, склонностью к риску, а также чувствительностью к угрозам, выбором адекватных или неадекватных (преувеличение или преуменьшение опасностей) способов реагирования в ситуациях опасности;

- принятие позиции принуждения или манипулирования может быть обусловлено высоким уровнем выраженности потребности в переживании чувства опасности, доминированием мотивации достижения, склонностью к риску, игнорированием опасностей; 
- принятие позиции ненасилия может быть детерминировано высоким уровнем выраженности потребности в обеспечении безопасности, стремлением не идти на неоправданный риск, высокой сензитивностью к угрозам, умением выбирать адекватные способы реагирования в ситуациях опасности;

- принятие позиции невмешательства, на наш взгляд, должно быть обусловлено доминированием потребности в переживании чувства безопасности, стремлением к избеганию неудач, повышенной осторожностью, желанием на всякий случай преувеличивать значение той или иной опасности.

Исследование осуществлялось в три этапа. На первом этапе анализировалась специальная литература, разрабатывалась теоретическая модель исследования. На втором - осуществлялись сбор материала и его обработка. На третьем этапе анализировались полученные результаты и делались выводы.

\section{ОБЗОР ОТЕЧЕСТВЕННОЙ И ЗАРУБЕЖНОЙ АИТЕРАТУРЫ ПО ТЕМЕ ИССАЕАОВАНИЯ}

Все названные нами позиции взаимодействия достаточно хорошо изучены в современной психологии.

Позиция принуждения рассматривается в контексте человеческой агрессивности. K настоящему времени сформировалось три подхода к обоснованию природы агрессивности. Это теория влечений, фрустрационная теория и теория социального научения. Исследователи указывают на существование двух мотивационных тенденций: тенденция к агрессии и к ее торможению (Хекхаузен, 2003). Первая тенденция обусловлена желанием личности достичь результатов, добиться успеха, стремлением к доминированию, самоутверждению, власти. Вторая тенденция - желанием избегать негативных последствий, страхом наказания и т. п.

В основе позиции манипулирования лежит специфический «вид психологического воздействия, искусное исполнение которого ведет к скрытому возбуждению у другого человека намерений, не совпадающих с его актуально существующими желаниями» (Аоценко, 2003: 58). Позицию манипулирования одним из первых описал Э. Шостром (Шостром, 2004), который выделил и дал характеристику типам человека-манипулятора. В отечественной психологии имеется немало исследований, посвященных характеристике техник манипулирования (Грачев, Мельник, 1999; Аоценко, 2003; Рюмшина, 2003).

Позиция ненасилия в большей мере анализируется с позиций общечеловеческих ценностей. Хорошо известны философско-этические обоснования ненасилия как принципа, отрицающего принуждение во всех его проявлениях. Аостаточно вспомнить взгляды $\Lambda$. Н. Толстого, Н. К. Рериха, М. Ганди, Ж. Семлена, М. А. Кинга, А. Швейцера. В обобщенном виде они проясняют современное толкование ненасилия как способности человека в каждый конкретный момент своей жизни из ряда альтернатив выбирать такие, которые несут в себе наименьший заряд принуждения (Маралов, Ситаров, 2015). В основе позиции ненасилия чаще всего лежат альтруистические мотивы, в частности мотивы помощи (Хекхаузен, 2003).

Позиция невмешательства является частным случаем проявления позиции смирения. В науке выделяют два вида смирения: «рабское смирение» и «аскетическое смирение» (Жилина, 2016). В первом случае смирение выступает как способ адаптации к сложным условиям существования. Во втором - смирение есть проявление свободы человека, когда он добровольно накладывает на себя определенные ограничения. В контексте 
нашего исследования мы анализируем лишь один из видов смирения, а именно - невмешательство. Эта позиция также неоднозначна по своим проявлениям. Аля одних людей позиция невмешательства определяется элементарной трусостью или безразличием. Аля других - это вариант проявления «идейности», т. е. сознательного ухода от проблем, обусловленного усталостью, депрессией, неверием в лучшее и т. А.

Что касается потребностей в безопасности и отношения людей к опасностям, то здесь также сложился ряд направлений исследований в этой сфере.

Прежде всего, ученых интересует содержательные характеристики проявлений потребности в безопасности. Например, согласно А. Маслоу (Маслоу, 2012), потребность в безопасности выступает как потребность в стабильности, в защите, в свободе от страха, тревоги и хаоса, как потребность в структуре, порядке, законе, ограничениях и в зависимости. В. В. Скворцов (Скворцов, 1986) выделяет три вида потребности в безопасности: потребность в обеспечении будущего, потребность в развитии своих сил и способностей, потребность в избегании неприятностей. В наших предыдущих исследованиях мы исходили из положения о том, что потребности в опасности и в безопасности могут проявляться как потребности в переживании определенных состояний и как потребности в специфической деятельности. В соответствии с этим мы выделяем следующие четыре типа потребностей: потребность в переживании чувства опасности и потребность в переживании чувства безопасности; потребность в поиске острых ощущений и потребность в обеспечении безопасности (Маралов и др., 2015: Электронный ресурс). В рамках гуманистического психоанализа потребность в безопасности анализируется в контексте жизненного пути человека. Представителями данного направления подчеркивается роль базового противоречия между потребностями человека в безопасности и многочисленными другими желаниями и устремлениями. Способы разрешения этого противоречия и определяют специфику жизненного пути человека. По К. Хорни, это стратегии, связанные либо с «движением к людям», либо с «движением от людей», либо с «движением против людей» (Хорни, 2007). По Э. Фромму, это стратегии, характеризующие пути «бегства человека от свободы» (Фромм, 1990).

Потребность в безопасности определяет и своеобразие типов отношения людей к опасностям. Впервые эта проблема была исследована в рамках клинической психологии как проблема отношения людей к болезни. Стимулом для организации такого рода исследований послужила идея А. Р. Аурии о «внутренней картине болезни» (Аурия, 1977). В последующем были выделены и описаны различные типы отношения людей к болезням. Обзор этих работ можно найти в монографии В. В. Николаевой (Николаева, 1987).

В наших исследованиях мы исходили из положения о том, что отношение к опасностям складывается из двух составляющих: сензитивности (чувствительности) к угрозам и выбора адекватных или неадекватных способов реагирования в ситуациях опасности. В результате были выделены и описаны восемь типов отношения людей к опасностям (Маралов и др., 2013). Исследование взаимосвязи потребностей в опасности и в безопасности с типом отношения людей к угрозам на выборке студентов показало, что здесь существуют определенные закономерности. Например, если в структуре потребностей преобладает потребность в обеспечении безопасности, то возрастает вероятность проявления адекватного сензитивного типа отношения к опасностям. Если же преобладает потребность в переживании чувства опасности, то индивид, скорее всего, будет игнорировать угрозы (Маралов, 2017). 
Выявление общих закономерностей взаимосвязи потребностей в безопасности и типов отношения людей к опасностям послужило толчком для дальнейшего исследования данной проблемы, а именно необходимости изучения влияния мотивации достижения и склонности к риску на отношение людей к угрозам. В частности, нами было установлено, что игнорирование опасностей связано с высоким уровнем готовности к риску, а стремление к преувеличению значения опасностей, наоборот, обусловлено повышенной осторожностью и доминированием мотивации избегания неудач (Маралов, Маралова, 2017).

Выявленные нами психологические особенности взаимосвязи потребностей в опасности и в безопасности, типов отношения к опасностям, мотивации достижения успеха и избегания неудач, а также склонности к риску позволили поставить вопрос о том, насколько все эти закономерности находят выражение в тех позициях, которые занимает человек в процессе взаимодействия с другими людьми. Это фактически и послужило основой для организации и проведения специального исследования, результаты которого мы излагаем в настоящей статье.

\section{МАТЕРИААЫ И МЕТОАЫ}

В процессе исследования были использованы следующие методы. Теоретические - анализ; сравнение; конкретизация; обобщение. Эмпирические - использовались авторские опросники на выявление позиций взаимодействия у студентов, потребностей в опасности и в безопасности, чувствительности к угрозам, выбора способов реагирования в ситуациях опасности, а также методики Т. Элерса на выявление мотивации достижения успеха и избегания неудач, тест Г. Шуберта, диагностирующий готовность дичности к риску. Методы математической статистики корреляционный анализ с применением линейного коэффициента корреляции Пирсона.

Опросник по выявлению у студентов уровня выраженности позииий взаимодействия (Маралов, Ситаров, 2018). Состоит из 40 вопросов-утверждений, по 10 вопросов на каждую позицию: принуждения, манипулирования, ненасилия, невмешательства. Испытуемым предлагались вопросы и по четыре варианта ответов на каждый из них, из которых им нужно было выбрать только один. За итоговый результат принималась сумма баллов, набранная каждым испытуемым по каждой шкале.

Опросник по вылвлению потребностей в опасности и 8 безопасности (Маралов и др., 2015: Электронный ресурс; Маралов и др., 2016). Включает в себя 15 утверждений. Пять из них направлены на выявление потребности в переживании чувства опасности, пять - на выявление потребности в переживании чувства безопасности, пять - потребности в обеспечении безопасности. На каждое утверждение предлагалось четыре варианта ответа: «да»; «скорее да, чем нет»; «скорее нет, чем да»; «нет». Этим вариантам приписывались баллы: «2», «1», «-1» и «-2». Суммарный индекс каждого вида потребностей вычислялся как сумма баллов по пяти утверждениям, диагностирующим ту или иную потребность. Сырые баллы переводились в стены.

Опросник сензитивности к угрозам (Маралов, Малышева, Нифонтова и др., 2012; Маралов, 2017). Состоит из 12 вопросов-заданий, моделирующих реальные типичные ситуации. Каждое задание опросника включает в себя формулировку некоторого утверждения и четыре варианта ответа. Испытуемому нужно выбрать только один из них, который в наибольшей степени соответствует его мнению. Полученные баллы по всем вопросам суммируются. В итоге получаем итоговый балл, который и характери- 
зует уровень сензитивности личности к опасностям. Разработана шкала переводов «сырых» баллов в стены.

Опросник по выявлению способов реагирования в ситуачиях опасности (Маралов, Малышева, Смирнова и др., 2012; Маралов, 2017). Состоит из 17 вопросов-утверждений, моделирующих поведение человека в реальных стандартных ситуациях, которые могут представлять угрозу. По каждому вопросу предлагается четыре варианта ответов, соответствующих четырем типам поведения личности: адекватному, преувеличивающему опасности, игнорирующему их, неопределенному. Испытуемый должен выбрать только один вариант, который в наибольшей степени соответствует его мнению. По каждому типу реагирования находился суммарный балл, после чего «сырые» баллы, как и в предыдущем случае, переводились в стены.

Тест T. Элерса на вылвление мотивачии достижения успеха (Райгородский, 2011). Опросник состоит из 41 вопроса, отвечать на которые необходимо либо "да», либо «нет». Результаты определяются как сумма баллов в соответствии с предлагаемым ключом. Чем выше балл, тем в больше степени выражена тенденция личности к достижению успеха.

Тест Т. Элерса на выявление мотивачии избегания неудач (Райгородский, 2011). Испытуемым предлагается список из 30 слов по три слова в группе. Необходимо к каждой строке выбрать только одно слово, которое наиболее точно характеризует индивида. Обработка проводится в соответствии с ключом. Чем выше набранный балл, тем в большей степени выражена мотивация избегания неудач.

Тест Г. Шуберта на выявление готовности к риску (Райгородский, 2011). Состоит из 25 вопросов, согласие с которыми оцениваются в баллах от -2 до +2. Общий балл готовности к риску вычисляется на основе суммирования баллов по всем вопросам.

Всего в исследовании приняли участие 122 студента Московского гуманитарного университета (70 человек) и Череповецкого государственного университета (52 человека) различного пола в возрасте от 18 до 22 лет. Обследование проводилось в 2018 г., в групповой форме. Каждому испытуемому давались тексты опросников и индивидуальные бланки для заполнения.

\section{РЕЗУ}

В ходе исследования был получен значительный массив информации, который был подвергнут корреляционному анализу с использованием линейного коэффициента корреляции Пирсона. Результаты отражены в таблице (см. с. 202-203).

Как видно из таблицы, нами получено значительное количество статистически значимых положительных и отрицательных коэффициентов корреляции.

Позиция принуждения положительно коррелирует с мотивацией достижения успеха, склонностью к риску, потребностью в переживании чувства опасности и игнорированием угроз, отрицательно - с мотивацией избегания неудач, потребностью в переживании чувства безопасности и потребностью в обеспечении безопасности. Позиция манипулирования положительно связана с мотивацией достижения успеха, готовностью к риску, потребностью в переживании чувства опасности, а также с сензитивностью к угрозам, отрицательно - с мотивацией избегания неудач. Позиция ненасилия обнаруживает незначительную положительную связь с мотивацией избегания неудач, с потребностью в обеспечении безопасности, сензитивностью к угрозам и выбором адекватных способов реагирования в ситуациях опасности, отрицательно - 


\begin{tabular}{|c|c|c|c|c|c|c|c|c|}
\hline 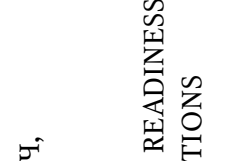 & $\begin{array}{c}\text { пәшоонорио } \\
\text { әинрgофпфонг И }\end{array}$ & 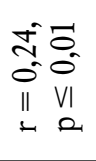 & 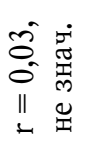 & 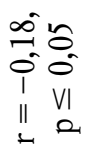 & 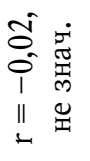 & 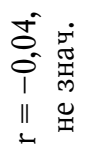 & 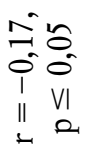 & 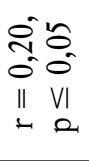 \\
\hline 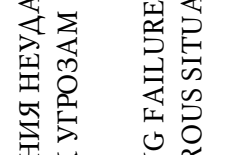 & 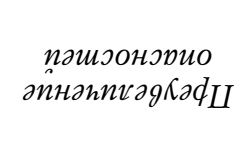 & 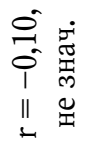 & 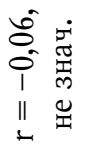 & 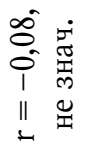 & 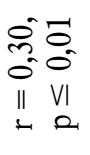 & 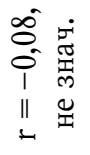 & 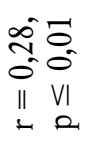 & 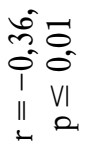 \\
\hline 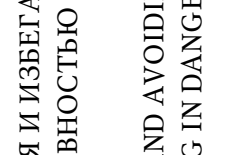 & 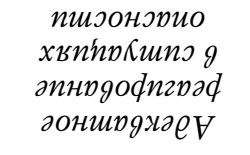 & 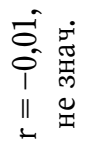 & 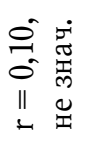 & 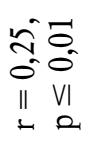 & 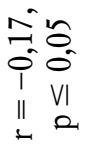 & 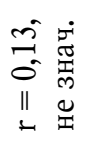 & 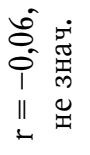 & 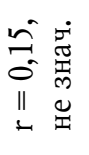 \\
\hline 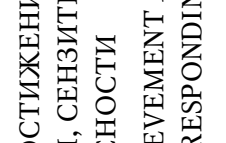 & 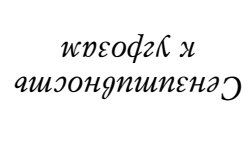 & 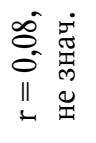 & 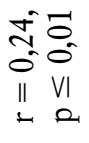 & 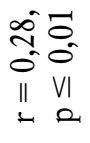 & 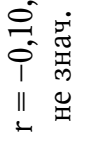 & 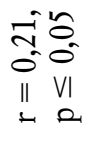 & 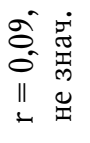 & 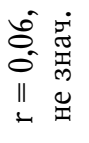 \\
\hline 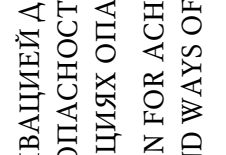 & 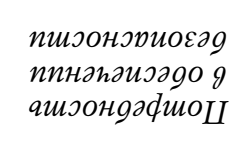 & 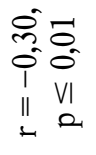 & 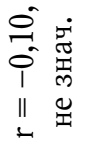 & 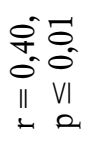 & 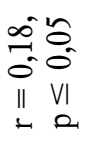 & 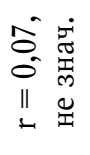 & 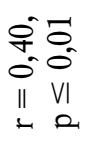 & 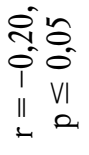 \\
\hline 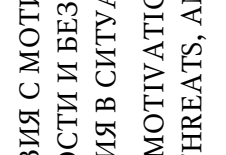 & 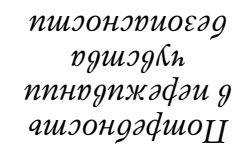 & $\begin{array}{ll}\infty & n \\
0 & 0 \\
0 & 0 \\
1 & V I \\
\| & 0\end{array}$ & 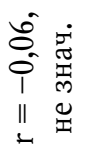 & 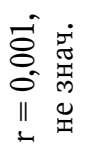 & 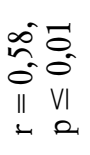 & $\begin{array}{ll}\infty & n \\
0 & 0 \\
0 & 0 \\
1 & V I \\
11 & 0\end{array}$ & 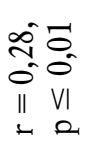 & 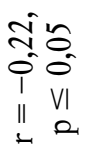 \\
\hline 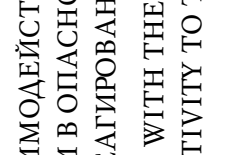 & 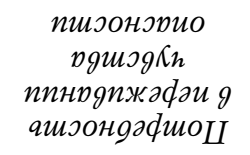 & 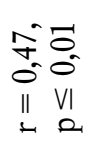 & 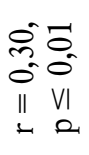 & 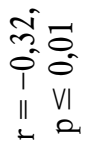 & 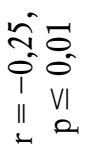 & 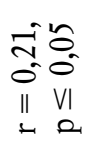 & 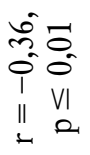 & 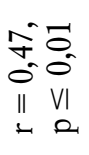 \\
\hline $\begin{array}{l}m \\
心 \\
心\end{array}$ & $\begin{array}{c}\text { Куоид } x \\
\text { qшхондошо I }\end{array}$ & 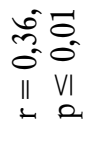 & 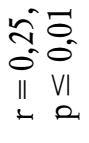 & 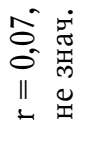 & 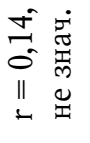 & 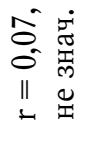 & 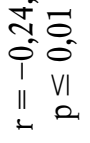 & 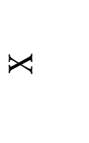 \\
\hline 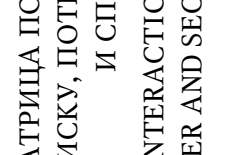 & 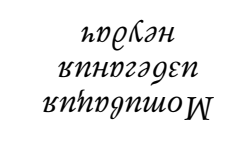 & 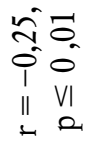 & 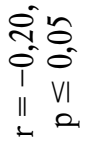 & 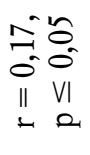 & 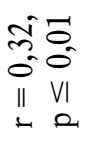 & 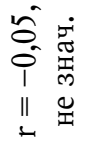 & $x$ & \\
\hline 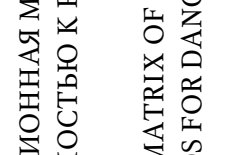 & $\begin{array}{c}\text { вхаиок } \\
\text { винажпшоое } \\
\text { впиряпшо }\end{array}$ & 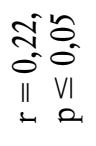 & 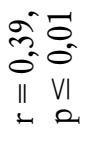 & 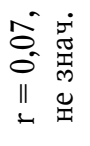 & 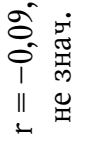 & $\rtimes$ & & \\
\hline 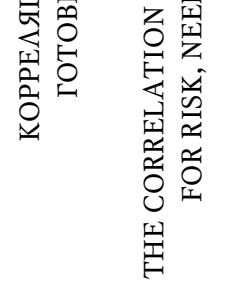 & 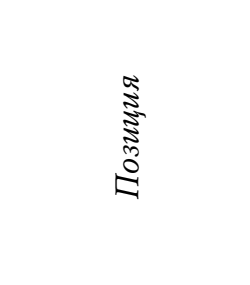 & 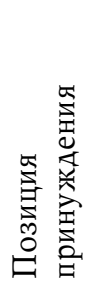 & 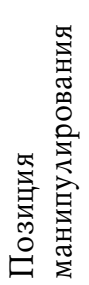 & 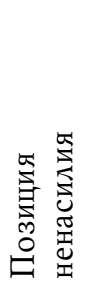 & 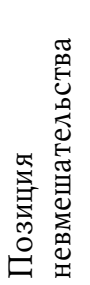 & 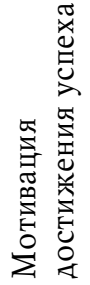 & 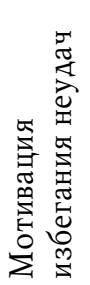 & 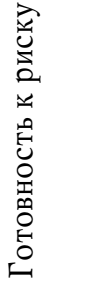 \\
\hline
\end{tabular}




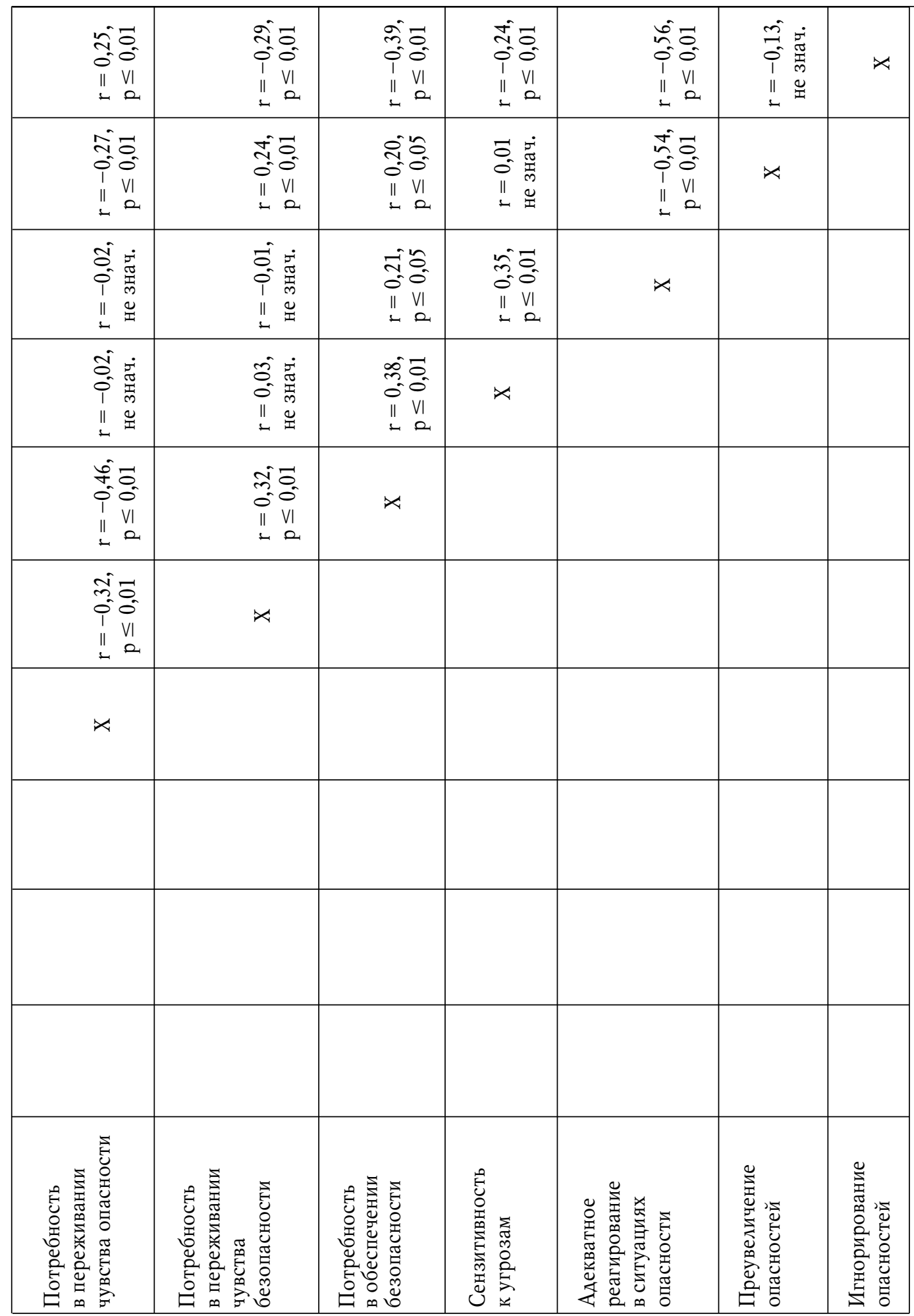


с потребностью в переживании чувства опасности и игнорированием угроз. Позиция невмешательства обнаружила положительную связь с мотивацией избегания неудач, потребностью в переживании чувства безопасности, потребностью в обеспечении безопасности, стремлением к преувеличению значения угроз, отрицательную - с потребностью в переживании чувства опасности и с выбором адекватных способов реагирования в ситуациях опасности. Выявлен также ряд значимых связей исследуемых факторов друг с Аругом.

С целью наглядного представления материала и облегчения последующей интерпретации данных полученные результаты были представлены в графической форме. Мы отобрали только значимые (не ниже $5 \%$ уровня) и только положительные коэффициенты корреляции. Результаты отображены на рисунке.

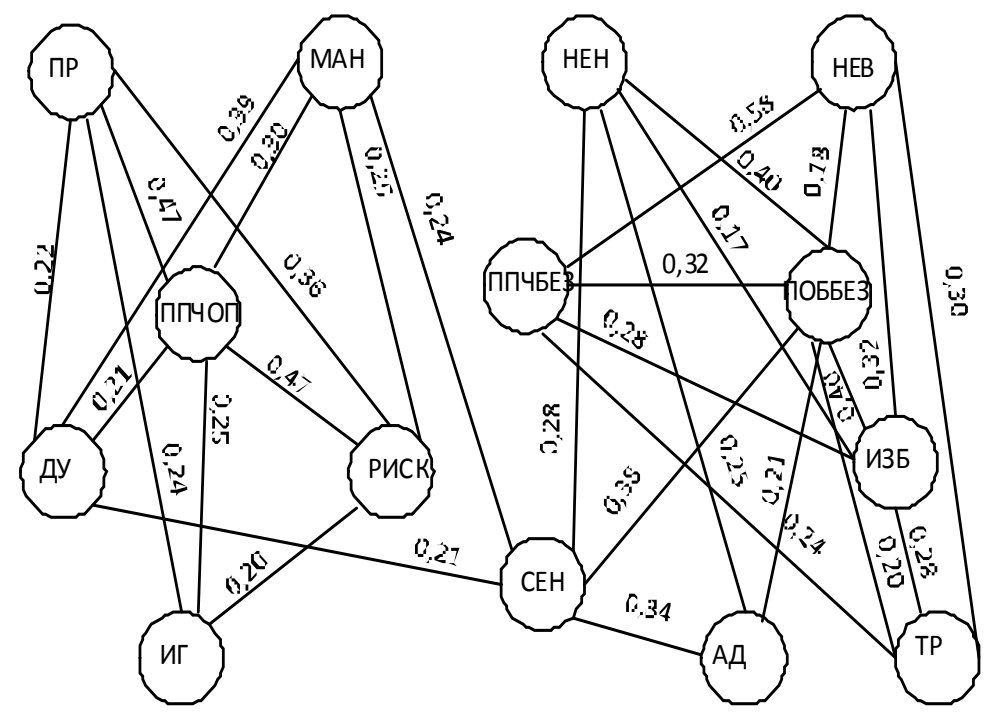

Взаимосвязь позичий взаимодействия с мотивачией достижения и избегания неудач, готовностью к риску, потребностями в опасности и безопасности, сензитивностью $\kappa$ угрозам и способами реагирования в ситуачиях опасности*

The interrelation between interaction positions and motivation for achievement and avoiding failure, readiness for risk, needs for danger and security, sensitivity to threats, and ways of responding in dangerous situations

*Прим.: На рисунке приняты следующие сокращения: ПР - позиция принуждения; МАН позиция манипулирования; НЕН - позиция ненасилия; НЕВ - позиция невмешательства; ППЧОП - потребность в переживании чувства опасности; ППЧБЕЗ - потребность в переживании чувства безопасности; ПОББЕЗ - потребность в обеспечении безопасности; АУ мотивация достижения успеха; ИЗБ - мотивация избегания неудачи; РИСК - готовность к риску; СЕН - сензитивность к угрозам; АА - выбор адекватных способов реагирования в ситуациях опасности; ТР - тревожный способ реагирования (преувеличение опасностей); ИГ - игнорирование опасностей.

На рисунке представлена система взаимосвязанных факторов, которые обусловливают проявления той или иной позиции. В качестве базовых факторов выступают потребности как источники активности дичности, влияющие на поведение индивида, 
в том числе и на принятие им той или иной позиции взаимодействия. Потребность в переживании чувства опасности положительно связана с мотивацией достижения успеха, склонностью к риску и стремлением игнорировать опасности. В свою очередь, все указанные факторы положительно коррелируют с позицией принуждения. В том случае, когда потребность в переживании чувства опасности связана со склонностью к риску, мотивацией достижения успеха, а мотивация достижения успеха сопровождается повышенной чувствительностью к угрозам, человек будет проявлять склонность к манипулированию. Потребность в переживании чувства безопасности положительно связана с мотивацией избегания неудачи, преувеличением значения опасностей, потребностью в обеспечении безопасности. Такое сочетание мотивационных факторов обусловливает принятие личностью позиции невмешательства. Причем связь позиции невмешательства с потребностью в переживании чувства безопасности почти в два раза теснее $(r=0,58$, при $\mathrm{p} \leq 0,001)$, чем с потребностью в обеспечении безопасности. Потребность в обеспечении безопасности положительно коррелирует с сензитивностью к угрозам, выбором адекватных способов реагирования в ситуациях опасности и с мотивацией избегания неудач. При таком сочетании факторов чаще проявляется позиция ненасилия.

\section{ЗАКАЮЧЕНИЕ}

Попытаемся проинтерпретировать полученные данные. Прежде всего, необходимо отметить значительную роль мотивационных факторов в принятии личностью той или иной позиции взаимодействия.

Если доминируют потребность в переживании чувства опасности, склонность к риску и стремление к игнорированию опасностей, то чаще человек будет принимать позицию принуждения. Возникает вопрос: почему? Мы полагаем, что первостепенное значение здесь имеет мотив достижения успеха. Индивид пытается любыми способами достичь своих целей, добиться результата. В тех случаях, когда он испытывает сопротивление со стороны других людей, вызванное их нежеланием следовать его целям и желаниям, он не находит другого способа, как использовать принуждение в тех или иных его формах. Положительным моментом здесь является высокая целеустремленность личности, стремление добиться результатов. Отрицательным - повышенная склонность к риску, игнорирование опасностей, желание достичь успехов любыми путями, в том числе и посредством принуждения.

Аругая категория людей способна предвидеть негативные последствия своего поведения, так как у них развита чувствительность к угрозам, которая определенным образом связана со стремлением к успеху, поэтому они предпочитают использовать не прямую форму принуждения, а косвенную, т. е. манипулирование. Положительным здесь, так же как и в предыдущем случае, является ориентация на успех, чувствительность к угрозам, желание снизить посредством манипулирования напряженность ситуации. Отрицательный момент - склонность к повышенному риску и желание не всегда социально одобряемыми способами, но обязательно добиться своего. Хорошо известно, что манипулирование не является за редким исключением оптимальным способом решения проблем, связанных с взаимоотношениями людей.

Если же доминирующее положение занимает потребность в обеспечении безопасности, то чаще всего личность проявляет чувствительность к угрозам и выбирает социально одобряемые способы реагирования на опасности, что находит выражение в предпочтении ненасильственного действия. В данном случае позиция ненасилия есть кон- 
кретный способ удовлетворения потребности в обеспечении безопасности. Сильной стороной данной позиции является ненанесение ущерба себе и противоположной стороне, слабой стороной - желание избегать острых ситуаций и неприятностей.

Если же преобладающей является потребность в переживании чувства безопасности, которая в ряде случаев может сочетаться с потребностью в обеспечении безопасности и с выраженным стремлением избегания неудач в сочетании с повышенной осторожностью (отрицательная корреляция с риском, см. табл., $r=-0,24$, при $\mathrm{p} \leq 0,01$ ), то индивид предпочитает отказываться от активных действий, т. е. принимать позицию невмешательства. Положительным моментом принятия данной позиции является удовлетворение потребности в переживании чувства безопасности, слабой стороной - тот факт, что часто возникшая жизненная проблема так и остается нерешенной, т. е. чувство безопасности может оказаться ложным.

Таким образом, проведенное исследование со всей очевидностью показало, что в процессе формирования у студентов способности к ненасильственному взаимодействию необходимо обращать внимание не только на ценностную сторону ненасилия как оптимального способа взаимодействия людей друг с другом, но и на мотивационные факторы. В первую очередь необходимо формировать потребность в обеспечении безопасности, вести работу по развитию чувствительности к угрозам, выработке умения адекватно реагировать на опасности, стимулировать мотивацию достижения с использованием социально приемлемых способов достижения успеха. А также показывать преимущества разумного риска в жизни, основанного на умении прогнозировать результаты и последствия своих действий и действий других людей.

Полученные результаты могут быть использованы при разработке специальных программ и технологий формирования у студентов - будущих педагогов, психологов, социальных работников, дефектологов, врачей и т. п. способности к ненасильственному взаимодействию.

\section{СПИСОК АИТЕРАТУРЫ}

Грачев, Г. В., Мельник, И. К. (1999) Манипулирование личностью: организация, способы и технологии информационно-психологического воздействия. М. : ИзА-во ИФРАН. 153 с.

Аоценко, Е. А. (2003) Психология манипуляции: феномены, механизмы и защита. М. : Речь. 304 с.

Жилина, У. В. (2016) Смирение и его формы // Вестник Челябинского государственного университета. № 5 (387). Философские науки. Вып. 40. С. 48-54.

Аурия, А. Р. (1977) Внутренняя картина болезни и иатрогенные заболевания. М. : Медицина. $111 \mathrm{c}$.

Маралов, В. Г. (2017) Взаимосвязь потребностей в безопасности с типами отношения людей к угрозам (на примере студенческой молодежи) // Международный научно-исследовательский журнал. № 1-3 (55). С. 128-134.

Маралов, В. Г., Кудака, М. А., Смирнова, О. В., Перченко, Е. А., Табунов, И. А. (2016) Разработка теста-опросника для диагностики у людей потребностей в безопасности // Ученые записки Череповецкого государственного университета. № 1. С. 12-17.

Маралов, В. Г., Кудака, М. А., Перченко, Е. А., Смирнова, О. В., Табунов, И. А. (2015) Индивидуально-типические особенности структуры потребностей в безопасности у студентов [Электронный ресурс]// Научно-методический электронный журнал Концепт. T. 13. URL: https://ekoncept.ru/2015/85518.htm (дата обращения: 12.04.2018).

Маралов, В. Г., Малышева, Е. Ю., Нифонтова, О. В., Перченко, Е А., Табунов, И. А. (2012) Разработка теста-опросника сензитивности к угрозам в юношеском возрасте // Перспективы науки. № 8. С. 32-37. 
Маралов, В. Г., Малышева, Е. Ю., Смирнова, О. В., Перченко Е. А., Табунов, И. А. (2012) Разработка теста-опросника по выявлению способов реагирования в ситуациях опасности в юношеском возрасте // Альманах современной науки и образования. № 12-1 (67). С. 92-96.

Маралов, В. Г., Малышева, Е. Ю., Маралова, Т. П., Перченко, Е. А., Смирнова, О. В., Табунов, И. А. (2013) Развивающаяся личность в зеркале угроз / под ред. В. Г. Маралова. Череповец : ФГБОУ ВПО ЧГУ. 144 с.

Маралов, В. Г., Маралова, Т. П. (2017) Влияние мотивационных факторов на отношение людей к опасностям // Научно-методический электронный журнал Концепт. № 1. С. 1-7.

Маралов, В. Г., Ситаров, В. А. (2015) Педагогика и психология ненасилия в образовании. М. : Юрайт. 424 с.

Маралов, В. Г., Ситаров, В. А. (2017) Характеристика позиций взаимодействия как форм выражения ценностей принуждения и ненасилия // Знание. Понимание. Умение. № 1. С. 131-146. DOI: $10.17805 /$ zpu.2017.1.9

Маралов, В. Г., Ситаров, В. А. (2018) Разработка диагностического опросника по выявлению позиций взаимодействия у студентов - будущих специалистов сферы психолого-педагогического сопровождения // Знание. Понимание. Умение. №1. С. 167-177. DOI: 10.17805/zpu. 2018.1.13

Маслоу, А. (2012) Мотивация и личность. СПб. : Питер. 352 с.

Николаева, В.В.(1987) Влияние хронической болезни на психику. М. : МГУ. 168 с.

Райгородский, А. Я. (2011) Практическая психодиагностика. Методики и тесты. М. : Бахpax-M. 672 c.

Рюмшина, А. И. (2003) Психология манипулирования людьми (ценностно-смысловой аспект). Ростов н/А. : Изд-во Ростовского государственного университета. 144 с.

Скворцов, В. В. (1986) Способы разрешения конфликтов. Методическая разработка. М. : Изд-во АНХ при Совете Министров СССР. 46 с.

Фромм, Э. (1990) Бегство от свободы. М. : Прогресс. 272 с.

Хекхаузен, Х. (2003) Мотивация и деятельность. СПб. ; М. : Питер ; Смысл. 860 с.

Хорни, К. (2007) Наши внутренние конфликты. Конструктивная теория неврозов. М. : Академический проект. 224 с.

Шостром, Э. (2004) Человек-манипулятор: Внутреннее путешествие от манипуляции к актуализации. М. : Апрель-Пресс ; Изд-во Ин-та психотерапии. 190 с.

Аата поступления: 12.06.2018 г.

\author{
STUDENTS' INTERACTION POSITIONS IN THE CONTEXT \\ OF ENSURING INDIVIDUAL PSYCHOLOGICAL SECURITY \\ V. G. MARALOV \\ CHEREPOVETS STATE UNIVERSITY, \\ A. A. Fortunatov, M. Yu. SHONin \\ MOSCOW UNIVERSITY FOR THE HUMANITIES
}

The relevance of the issue is stipulated by the importance of identifying the factors that cause people to adopt a position of interaction: coercion, manipulation, non-coercion and non-interference, which can be evaluated from the security perspective. The purpose of the research was to identify the relationship between the positions of interaction and the needs for danger and security, motivation for success and failure avoidance, appetite for risk, sensitiveness (susceptibility) to threats and the choice of adequate or inadequate response in situations of danger. The author's questionnaires were used to identify the positions of interaction among students, needs for danger and security, sensitivity to threats, choice of adequate or inadequate ways of responding in situations of danger, as well as T. Elers' tests to identify the motivation for success and avoiding failure, G. Schubert's test, diagnosing the readiness of the individual to risk. In total, 122 students of Moscow University for the Humanities and Cherepovets State University aged from 18 till 22 years old took part in the research, which was conducted in 2018. 
As a result, a positive correlation was found between the position of coercion and the need to experience a sense of danger, the desire to ignore threats, the motivation for achievement. The position of manipulation found the same connections; besides, a relation with sensitivity to threats was revealed. The position of non-coercion correlates positively with the need for security, the desire to avoid failure, sensitivity to threats and the choice of adequate ways of responding. The position of non-interference is positively related, first of all, to the need for a sense of security, as well as to the need for ensuring security, pronounced desire to avoid failure, the desire to exaggerate the importance of dangers. The conducted research has clearly shown that in the process of developing students' ability to interact nonviolently it is necessary to pay attention not only to the value side of nonviolence as an optimal way of people's interaction with each other, but also to motivational factors, in particular, the formation of the need for ensuring security. The obtained results can be used in the development of special programmes and technologies instilling in students - future teachers, psychologists, social workers, speech pathologists, doctors, etc. the skills of nonviolent interaction.

Keywords: interaction; interaction positions; pedagogy of non-coercion; motivation; need for danger; need for security; motivation for achieving success; appetite for risk; sensitivity to threats; psychology of personal security

\section{REFERENCES}

Grachev, G. V. and Mel'nik, I. K. (1999) Manipulirovanie lichnost'iu: organizatsiia, sposoby $i$ tekb-nologii informatsionno-psikbologicheskogo vozdeistviia. Moscow, Izd-vo IFRAN. 153 p. (In Russ.).

Dotsenko, E. L. (2003) Psikbologiia manipuliatsii: fenomeny, mekbanizmy i zashchita. Moscow, Rech'. 304 p. (In Russ.).

Zhilina, U. V. (2016) Smirenie i ego formy. Vestnik Cheliabinskogo gosudarstvennogo universiteta, no. 5 (387), Filosofskie nauki. Vol. 40, pp. 48-54. (In Russ.).

Luriia, A. R. (1977) Vnutrenniaia kartina bolezni $i$ iatrogennye zabolevaniia. Moscow, Meditsina. 111 p. (In Russ.).

Maralov, V. G. (2017) Vzaimosviaz' potrebnostei v bezopasnosti s tipami otnosheniia liudei k ugrozam (na primere studencheskoi molodezhi). Mezhdunarodnyi nauchno-issledovatel'skii zhurnal, no. 1-3 (55), pp. 128-134. (In Russ.).

Maralov, V. G., Kudaka, M. A., Smirnova, O. V., Perchenko, E. L. and Tabunov, I. A. (2016) Razrabotka testa-oprosnika dlia diagnostiki u liudei potrebnostei v bezopasnosti. Uchenye zapiski Cherepovetskogo gosudarstvennogo universiteta, no. 1, pp. 12-17. (In Russ.).

Maralov, V. G., Kudaka, M. A., Perchenko, E. L., Smirnova, O. V. and Tabunov, I. A. (2015) Individual'no-tipicheskie osobennosti struktury potrebnostei v bezopasnosti u studentov. Kontsept, vol. 13 [online] Available at: https://e-koncept.ru/2015/85518.htm (access date: 12.04.2018). (In Russ.).

Maralov, V. G., Malysheva, E. Iu., Nifontova, O. V., Perchenko, E L. and Tabunov, I. A. (2012) Razrabotka testa-oprosnika senzitivnosti k ugrozam v iunosheskom vozraste. Perspektivy nauki, no. 8, pp. 32-37. (In Russ.).

Maralov, V. G., Malysheva, E. Iu., Smirnova, O. V., Perchenko E. L. and Tabunov, I. A. (2012) Razrabotka testa-oprosnika po vyiavleniiu sposobov reagirovaniia $\mathrm{v}$ situatsiiakh opasnosti v iunosheskom vozraste. Al'manakb sovremennoi nauki i obrazovaniia, no. 12-1 (67), pp. 92-96. (In Russ.).

Maralov, V. G., Malysheva, E. Iu., Maralova, T. P., Perchenko, E. L., Smirnova, O. V. and Tabunov, I. A. (2013) Razvivaiushchaiasia lichnost' v zerkale ugroz / ed. by V. G. Maralov. Cherepovets, FGBOU VPO ChGU. 144 p. (In Russ.).

Maralov, V. G. and Maralova, T. P. (2017) Vliianie motivatsionnykh faktorov na otnoshenie liudei k opasnostiam. Kontsept, no. 1, pp. 1-7. (In Russ.).

Maralov, V. G. and Sitarov, V. A. (2015) Pedagogika $i$ psikbologiia nenasiliia $v$ obrazovanii. Moscow, Iurait. 424 p. (In Russ.). 
Maralov, V. G. and Sitarov, V. A. (2017) Kharakteristika pozitsii vzaimodeistviia kak form vyrazheniia tsennostei prinuzhdeniia i nenasiliia. Znanie. Ponimanie. Umenie, no. 1, pp. 131-146. DOI: 10.17805/zpu.2017.1.9 (In Russ.).

Maralov, V. G. and Sitarov, V. A. (2018) Razrabotka diagnosticheskogo oprosnika po vyiavleniiu pozitsii vzaimodeistviia u studentov - budushchikh spetsialistov sfery psikhologo-pedagogicheskogo soprovozhdeniia. Znanie. Ponimanie. Umenie, no. 1, pp. 167-177. DOI: 10.17805/zpu.2018.1.13 (In Russ.).

Maslou, A. (2012) Motivatsiia i lichnost'. St. Petersburg, Piter. 352 p. (In Russ.).

Nikolaeva, V. V. (1987) Vliianie kbronicheskoi bolezni na psikbiku. Moscow, MGU. 168 p. (In Russ.).

Raigorodskii, D. Ia. (2011) Prakticheskaia psikbodiagnostika. Metodiki i testy. Moscow, Bakhrakh-M. 672 p. (In Russ.).

Riumshina, L. I. (2003) Psikbologiia manipulirovaniia liud'mi (tsennostno-smyslovoi aspekt). Rostov n/D., Izd-vo Rostovskogo gosudarstvennogo universiteta. 144 p. (In Russ.).

Skvortsov, V. V. (1986) Sposoby razresheniia konfliktov. Metodicheskaia razrabotka. Moscow, Izd-vo ANKh pri Sovete Ministrov SSSR. 46 p. (In Russ.).

Fromm, E. (1990) Begstvo ot svobody. Moscow, Progress. 272 p. (In Russ.).

Khekkhauzen, Kh. (2003) Motivatsiia $i$ deiatel'nost'. St. Petersburg, Moscow, Piter ; Smysl. 860 p. (In Russ.).

Khorni, K. (2007) Nashi vnutrennie konflikty. Konstruktivnaia teoriia nevrozov. Moscow, Akademicheskii proekt. 224 p. (In Russ.).

Shostrom, E. (2004) Chelovek-manipuliator: Vnutrennee puteshestvie ot manipuliatsii $k$ aktualizatsii. Moscow, Aprel'-Press ; Izd-vo In-ta psikhoterapii. 190 p.

Submission date: 12.06.2018.

Маралов Владимир Георгиевич - доктор психологических наук, профессор кафедры психологии Череповецкого государственного университета. Адрес: 162600, Россия, Вологодская

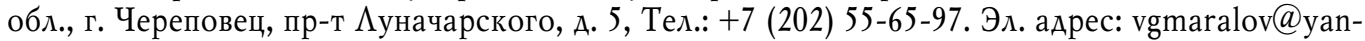
dex.ru

Фортунатов Артем Александрович — кандидат педагогических наук, доцент кафедры педагогики и психологии высшей школы Московского гуманитарного университета. Адрес: 111395, Россия, г. Москва, ул. Юности, д. 5 Тел.: +7 (499) 374-74-59. Эл. адрес: art_fortunatov@mail.ru

Шонин Максим Юрьевич - аспирант кафедры педагогики и психологии высшей школы Московского гуманитарного университета. Адрес: 111395, Россия, г. Москва, ул. Юности, д. 5 Тел.: +7 (499) 374-74-59. Эл. адрес: st_max_92@mail.ru. Научный руководитель - А-р пед. наук, проф. В. А. Ситаров.

Maralov Vladimir Georgiyevich, Doctor of Psychology, Professor, Department of Psychology, Cherepovets State University. Postal address: 5, Lunacharskogo Ave., Cherepovets, Vologda Region, Russian Federation, 162600. Tel.: +7 (921) 252-40-57. E-mail: vgmaralov@yandex.ru

Fortunatov Artyom Aleksandrovich, Candidate of Pedagogy, Associate Professor, Department of the Pedagogy and Psychology of Higher School, Moscow University for the Humanities. Postal address: 5, Yunosti St., Moscow, Russian Federation, 111395. Tel.: +7 (499) 374-74-59. E-mail: art fortunatov@mail.ru

Shonin Maksim Yuryevich. Postgraduate Student, Department of the Pedagogy and Psychology of Higher School, Moscow University for the Humanities. Postal address: 5, Yunosti St., Moscow, Russian Federation, 111395. Tel.: +7 (499) 374-74-59. E-mail: st_max_92@mail.ru. Scientific Advisor - V. A. Sitarov, Doctor of Pedagogy, Professor 